\title{
The Peripheral Turn in Global Urban Studies: Theory, Evidence, Sites
}

Xuefei Ren

\section{(2) OpenEdition}

12 Journals

Electronic version

URL: https://journals.openedition.org/samaj/7413

DOI: $10.4000 /$ samaj.7413

ISSN: $1960-6060$

Publisher

Association pour la recherche sur l'Asie du Sud (ARAS)

Electronic reference

Xuefei Ren, "The Peripheral Turn in Global Urban Studies: Theory, Evidence, Sites", South Asia

Multidisciplinary Academic Journal [Online], 26 | 2021, Online since 04 May 2021, connection on 11 May 2021. URL: http://journals.openedition.org/samaj/7413 ; DOI: https://doi.org/10.4000/samaj.7413

This text was automatically generated on 11 May 2021

\section{(c) (i) (9)}

This work is licensed under a Creative Commons Attribution-NonCommercial-NoDerivatives 4.0 International License. 


\title{
The Peripheral Turn in Global Urban Studies: Theory, Evidence, Sites
}

\author{
Xuefei Ren
}

1 On the leafy campus of the University of Chicago sits the eminent Gothic-style Social Science Building, where one can find the original concentric map of urban expansion, hand-drawn by urban sociologists Robert E. Park and E. W. Burgess in the 1920s. As founding members of the Chicago School of urban sociology, Park and Burgess proposed this map to capture universal patterns of urban growth-that is, growth radiating from the center (i.e., downtown) to the periphery (i.e., suburbs) (Park and Burgess [1925] 2019). They applied the concentric model beyond Chicago to study cities as far away as China, India, and Brazil (Ren 2019). In their view, the center was the beating heart of the city, the site for prominent government institutions and powerful corporations. As one moved away from the center, one encountered other settlement types, such as working-class neighborhoods, ethnic enclaves, and sleepy residential suburbs on the urban periphery. For the first generation of the Chicago School, the center dominated the periphery, as the most important urban activities all pivoted around the center-in the case of Chicago, the "Loop."

2 The Chicago School's concentric model of urban expansion was continuously challenged in the second half of the $20^{\text {th }}$ century. Among its major critics were the members of the Los Angeles School of urban geographers, who proclaimed that it was the periphery that reorganized the center. As evidence, they pointed to the sprawling Los Angeles, where downtown played a minor role in the social and economic life of the metropolitan region (Dear 2002). This deliberate shift away from the center has continued since the intervention by the L.A. school in the 1990s, and more recent examples include the scholarship on global suburbanism (Keil 2017; Hamel and Keil 2015; Güney, Keil and Üçoğlu 2019) and planetary urbanization (Brenner 2014), as well as studies on urban peripheries in the global South (Kennedy and Sood 2016; Gururani 2020), including this special issue on India. A century after the invention of 
urban sociology, the paradigm of urban studies has been inverted, with the "periphery" taking center stage for urban inquiry.

This special issue on Indian urbanization, curated by three leading scholars on India, is the latest intervention in the peripheral turn in global urban studies. The collection of essays examines wide-ranging socio-spatial transformations unfolding on the urban periphery of Indian cities, such as labor migration, land grabs, property-led development, residential segregation, and shifting governance institutions. Based on mixed methods-historical analysis, oral history, ethnography, quantitative analyses, and visual documentation-these studies spotlight the incompleteness of city-making on the urban edge, and they argue that inherited social structures, landholding patterns, and agrarian economies in Indian villages strongly shape the nascent urban development on the periphery. In this essay, I situate the new scholarship on periurban India in the larger field of global urban studies by discussing two issues: first, what can be gained by studying the urban periphery-both in India and other placesand second, what the blind spots are in the peripheral turn that merit further investigation.

\section{Where is the periphery?}

4 The term "periphery" is used in this collection of essays in at least four different ways, which well represent its wider use in global urban studies in general. First, it denotes peripheral locations, such as the fringe areas of large cities, small towns, and the rural hinterlands. This approach, which shifts the focus away from downtown (or the city center), is consistent with the Los Angeles School's critique of the Chicago School, in pointing out the integration of suburbs and other settlements on the urban edge into the world economy. In addition to studying the urban edge of large cities, the special issue also pinpoints the significance of studying small towns and villages, which have been undergoing in-situ urbanization and becoming increasingly incorporated in the national and global urban networks. Prioritizing small towns and rural villages is especially relevant in the Indian context, where nearly one third of the urban population growth in the last two decades took place in urbanizing small towns, as locals moved away from agriculture and took jobs in manufacturing and services (Bhide and Burte 2019). Consistent with the perspective of "subaltern urbanization"-urban transformation in small towns (Mukhopadhyay, Zérah and Denis 2020)-the authors in this special issue underscore the importance of studying the bottom-up urbanization happening outside India's major cities such as Delhi and Mumbai. Attention to smaller settlements can deepen our understanding of the variations in urban structures and processes in large and diverse countries such as India.

The second meaning of "periphery" here denotes the global South. This approach can be traced back to Immanuel Wallerstein's work on the world-system perspective in the 1970s, which divided the world into three zones-the core, the semi-periphery, and the periphery (Wallerstein 2004). The peripheral zone included the late developing countries that heavily relied upon exports of raw materials for foreign currency, with which these countries purchased advanced machinery and technologies from the core countries. Wallerstein's world-system perspective was masterfully adopted by urban scholars in the 1980s, as seen in the scholarship on global cities (Sassen 1991). However, as rightfully pointed out by scholars such as Jennifer Robinson, much of the global city 
literature has focused on the most powerful financial centers and ignored smaller cities "off the map" (Robinson 2002, 2006). Since the mid-2000s, there has been a strong pushback against the global city literature that focused on the financial powerhouses. As much of urban population growth has been happening in the global South, it is a natural form of awakening to study non-Western cities in developing countries, a peripheral zone that was neglected until recently. Therefore, the new urban scholarship on the global South complements the global city literature and concludes the full circle of adapting Wallerstein's world-system perspective to critical urban studies.

6 The shift of research gravity to the global South is also a theoretical move. By studying locations in the global South, such as India, scholars argue that Western-centric urban theory can be liberated to allow more innovation. This leads to the third meaning of "periphery": the periphery of urban theory, or theorization from the margins, such as sites outside North America and Western Europe. Indeed, the contributions to this special issue show ample evidence of new theoretical frameworks emerging from studying Indian cities. For example, Sood (this issue) proposes a typology of governance of urban peripheries, based on studies of Noida and Hyderabad-specialized, privatized, transitional, and exceptional. These logics of governance can be observed, to varying degrees, in suburbs and urban peripheries in Western cities as well-from Chicago to Toronto, from Los Angeles to Paris. Xie (this issue) complicates the notion of segregation-a key concept derived from American cities with entrenched racial inequalities (Garrido 2020). He shows how segregation takes different forms in cities in China and India, such as interspersion of gated communities and informal settlements, mixed-income living within the same residential compound, and vertical cohabitation in individual buildings. Key concepts that originated from North American cities, such as segregation, should be opened up to account for more diverse patterns of urban structures and processes (Garrido, Ren and Weinstein 2020).

7 The last meaning of "periphery" is metaphorical and refers to marginal populations and their precarious living. The essays in this issue study many such disadvantaged groups, such as migrants working in kiln workshops on the outskirts of Delhi (Mishra, this issue) and Dalit farmers trying to eke out a living in the midst of Bengaluru's real estate boom (Upadhya and Rathod, this issue). With fragmented municipal institutions, the poor and marginalized are unlikely to succeed in challenging the exploitative systems in which they are embedded-whether it is the lack of job security and social safety net for casual laborers, or land assembly for real estate development, which is dominated by the upper castes. The balance of power clearly tilts toward the propertied class, who have the social, political, and cultural capital to forge connections with state bureaucracies and private investors, in order to benefit from land speculation on the periphery.

\section{What can be gained?}

8 Studying the periphery-read as urban fringes, the global South, theoretical margins, and vulnerable populations-can yield insights into local particularities and can also lead to theoretical innovation. As the essays in this collection demonstrate, focusing on the periphery can deepen our understanding of the people and communities living on the metropolitan edge and in small towns; furthermore, it leads to important first steps 
for theorizing about urban structures, governance, and social relations in these rapidly urbanizing communities.

9 This special issue identifies three features of social relations and governance apparatus on the urban fringes of Indian cities. The first is the inherited caste system that perpetuates the reproduction of inequality. Unlike in large cities, where residential and occupational mobility has rendered caste-based politics less palpable in urban life, in the rural communities on the urban periphery, local life and the political economy still pivot around the rigid caste hierarchy. While the upper castes can diversify their financial assets across sectors-in trade, agriculture, manufacturing, and real estatethe lower castes are less able to do so and tend to lose out in property-led development. However, the latter are not entirely powerless, as in-depth ethnographic work by Upadhya and Rathod (this issue) tells us: some Dalit farmers have become land brokers and political activists, and through the court system, they increasingly challenge the encroachment on common land by upper caste groups.

The second feature of urban fringes in India is the extremely fragmented governing structures. Compared to other countries, India is known for its weak municipal institutions (Ren 2020). The institutional void is even more pronounced on the urban periphery, which often falls outside the jurisdictions of municipal governments. This vacuum of authority has given rise to an array of power brokers who jockey for influence-such as non-representative para-statal agencies, newly formed municipal authorities, and existing village panchayats. The lack of a consolidated metropolitan authority further poses challenges for delivering adequate infrastructure and services to communities, who are already victims of environmental degradation, land dispossession, and state neglect (Sood, this issue).

11 A final distinctive feature of India's urban periphery is the semi-permanence of the rural. The rural economy, lifestyle, governance structures, and social relations still stubbornly persist, and they render the city-making process incomplete, as collectively argued by the contributors in this issue. In this regard, the urban peripheries in India differ from metropolitan edges in other countries such as China, where middleclass new towns and manufacturing zones have wiped out rural settlements, governance structures, and ways of life. Scholars have conceptualized the incomplete urban transition in India as "agrarian urbanism" or "subaltern urbanization," to underscore how the urban and rural seep into each other (Gururani 2020; Mukhopadhyay, Zérah and Denis 2020; Rathi, this issue).

These empirical insights are important first steps for further theorization of urban structures and processes in India. Here, theorization can be read as abstraction, generalization, and contemplation (Levine 1997). From the empirical, the particular, and the practical (e.g., policy recommendations and implications), we can proceed to urban theory construction, including but not limited to (1) articulating and disambiguating major concepts, such as segregation; (2) constructing conceptual frameworks to explain processes such as land assembly in Indian cities; (3) developing typologies, such as typologies of metropolitan governance; (4) problem-finding, such as how governance is possible without governments, as in the case of census towns on the peripheries; and (5) identifying new analytical angles, such as revisiting "caste" and examining how the persistent caste hierarchy co-produces the urban in India. 


\section{What is next?}

13 The peripheral turn presented a paradigm shift in global urban studies. So much can be gained-in both empirical discovery and theoretical construction-when we shift our focus from the city center to the urban edge, from global cities to ordinary cities and rural hinterlands (Robinson 2016). However, with every analytical strategy there are blind spots, and the scholarship on urban peripheries is no exception. I identify three issues that can be better attended to by scholars writing about urban peripheries; two concern topics of investigation, and one concerns methodology.

The first is the question of how the periphery articulates with the center, in the form of city centers (downtowns), central cities (such as global cities), or "nerve centers" of policy making, such as bureaucracies within different levels of the government. By focusing on the outlying areas on the metropolitan edge, the scholarship on peri-urban India tends to leave out the center. The periphery is linked in multiple ways to the center, and what happens at the center invariably shapes the urban structures and processes on the periphery. Therefore, instead of focusing on "either" the center "or" the periphery, it is more constructive to study the linkages and connections between the two and examine how they reshape and reproduce one another. To take the example of Mishra's essay on marginal laborers working in kiln factories on the outskirts of Delhi, as the author indicated, these workers' livelihood is deeply intertwined with the building cycles in the national capital region; labor policies made by the government and judicial decisions regarding pollution control from the Indian Supreme Court have had significant repercussions on these migrant laborers (Mishra, this issue).

A second issue that needs attention is comparative methods. Many use comparisons in their investigation into urban peripheries, but the comparative method can be made more effective with some theoretical guidance (Storper and Scott 2016). In this special issue, some authors have incorporated a comparative gesture: segregation in Hyderabad is compared with that in Chengdu, China; upper caste farmers are compared with Dalit peasants in their struggle over land in Bengaluru; and the governing structures of Noida new town are compared to those of the Greater Hyderabad region. Although these comparisons have yielded substantial insights, there is still considerable scope for strengthening comparative methods. As a good starting point, we need to have a theoretical sense of the significance and properties of the cases before comparing them (Scott and Storper 2015). For more structured comparison, we should attend to at least four issues: case selection, identification of a central puzzle, incorporation of a historical perspective, and articulation of wider implications (Ren 2020b). More specifically, cases need to be selected to reveal social structures and mechanisms (Steinmetz 2004); the research, ideally, should be guided by a puzzle, in the form of a causal question; a historical perspective-identifying historical junctures, critical events, and turning points-is necessary to shed light on the contemporary development outcomes; and we need to go beyond our small number of case studies and think about wider implications-how conclusions from the cities we study can be applied to other places, and if they can't, why not. More structured comparisons can further advance the peripheral turn in urban studies.

16 Finally, the changing culture of communities living on the urban periphery also needs to be studied. By "culture," I refer to the changing lifestyles, traditions, and norms in 
urbanizing small towns and villages. As the Chicago School reminded us, the urban should not be defined only in terms of population size, density, and heterogeneity; instead, it should be studied from a cultural perspective, such as "ways of life" (Wirth 1938). The same can be said about the inquiries on India's urban periphery, which is the site for rapidly changing communities who adapt their ways of life as their towns urbanize. From the urban India scholarship, we have learned much about these communities regarding land speculation, migration, and political patronage, but we don't know how various groups-the middle class, migrants, farmers, and power brokers-make sense of the social changes that they live through, and how they change their ways of life to ride the wave of urban growth, or merely to survive.

By way of conclusion, I share an ethnographic encounter in a village on the outskirts of Delhi, to illustrate why cultural change needs to be studied. In 2017, I accompanied Shubhra Gururani, one of the editors of this issue, during her fieldwork in the urban villages in Gurugram. We visited a well-to-do family of farmers belonging to the Jat caste. While Gururani interviewed the family's elder about the landowning patterns in the village, I conversed with the two little boys, five and six years old, who were incredibly curious about me-a foreigner-in their house. Both boys spoke English, and they showed me their favorite toys, including Doraemon, a Japanese anime character hugely popular in Asia; then they guided me to their bedroom, which had a dedicated study space, with a small desk and a chair tucked in a corner, and textbooks neatly organized on top of the desk. They showed me framed pictures of family trips to ski resorts in north India and to the sunny beaches in Goa. For a few minutes, I forgot I was visiting a "rural" family in a "village" in India. These two boys had more in common with other middle-class children in China and the U.S. than with their peers in the impoverished parts of rural India. When we left, I couldn't help wondering what the boys would be doing when they grew up. They have a whole world of possibilities in front of them and staying back in the village is an unlikely option. Ways of life are rapidly changing in the communities on the urban periphery, and they need to be studied if we want to gain a deeper understanding of the social change engulfing these communities.

India's urban transition is incomplete and fraught with tensions, as made clear in this special issue with in-depth ethnographic studies on governance, land acquisition, and segregation. These investigations, firmly grounded in the urban political economy tradition, can benefit from incorporating a cultural perspective. By being mindful of not only infrastructure, but also culture, we can gain a holistic understanding of the urban transformation sweeping through India's small towns and villages and anticipate fresh insights and theoretical gains along the way.

\section{BIBLIOGRAPHY}

Bhide, Amita, and Himanshu Burte. 2019. Urban Parallax: Policy and the City in Contemporary India. New Delhi: Yoda Press. 
Brenner, Neil. 2014. Implosions/Explosions: Towards a Study of Planetary Urbanization. Berlin: Jovis. Dear, Michael. 2002. "Los Angeles and the Chicago School: Invitation to a Debate." City and Community 1(1):5-32.

Garrido, Marco. 2020. "Reconceptualizing Segregation from the Global South." City and Community. Retrieved May 3, 2021 (https://doi.org/10.1111/cico.12504).

Garrido, Marco, Xuefei Ren, and Liza Weinstein. 2020. “Toward a Global Urban Sociology: Keywords.” City \& Community. Retrieved May 3, 2021 (https://doi.org/10.1111/cico.12502).

Güney, K. Murat, Roger Keil and Murat Üçoğlu. 2019. Massive Suburbanization: (Re)Building the Global Periphery, One Large Scale Housing Project at a Time. Toronto: University of Toronto Press. Gururani, Shubhra. 2020. "Cities in a World of Villages: Agrarian Urbanism and the Making of India's Urbanizing Frontiers.” Urban Geography 41(7):971-89.

Hamel, Pierre, and Roger Keil. 2015. Suburban Governance: A Global View. Toronto: University of Toronto Press.

Keil, Roger. 2017. Suburban Planet: Making the World Urban from the Outside In. Cambridge: Polity.

Kennedy, Loraine, and Ashima Sood. 2016. “Greenfield Development as Tabula Rasa: Rescaling, Speculation and Governance on India's Urban Frontier." Economic \& Political Weekly 51(17):41-109.

Levine, Donald. 1997. “Social Theory as a Vocation." Perspectives 19(2):1-16.

Mukhopadhyay, Partha, Marie-Hélène Zérah, and Éric Denis. "Subaltern Urbanization: Indian Insights for Urban Theory." International Journal of Urban and Regional Research 44(4):582-98.

Park, Robert E. and E.W. Burgess. [1925] 2019. The City. Chicago: University of Chicago Press.

Ren, Xuefei. 2019. "Robert Park in China: From the Chicago School to Urban China Studies."

Pp. 1-16 in The City in China: Perspectives on Contemporary Urbanism, edited by R. Forrest, J. Ren, and B. Wissink. Bristol: Policy Press.

Ren, Xuefei. 2020a. Governing the Urban in China and India: Land Grabs, Slum Clearance, and the War on Air Pollution. Princeton: Princeton University Press.

Ren, Xuefei. 2020b. "From a Comparative Gesture to Structured Comparison: An Analysis of Air Pollution Control in Beijing and Delhi." Cambridge Journal of Regions, Economy and Society 13(3):46173.

Robinson, Jennifer. 2002. "Global and World Cities: A View from Off the Map." International Journal of Urban and Regional Research 26(3):531-54.

Robinson, Jennifer. 2006. Ordinary Cities: Between Modernity and Development. London: Routledge.

Robinson, Jennifer. 2016. "Comparative Urbanism: New Geographies and Cultures of Theorizing the Urban." International Journal of Urban and Regional Research 40(1):187-99.

Sassen, Saskia. 1991. The Global City: New York, London, Tokyo. Princeton: Princeton University Press.

Scott, Allen and Michael Storper. 2015. "The Nature of Cities: The Scope and Limits of Urban Theory." International Journal of Urban and Regional Research 39(1):1-15.

Steinmetz, George. 2004. "Odious Comparisons: Incommensurability, the Case Study, and 'Small N's." Sociological Theory 22(3):371-400.

Storper, Michael and Allen Scott. 2016. "Current Debates in Urban Theory: A Critical Assessment." Urban Studies 53(6):1114-36. 
Wallerstein, Immanuel. 2004. World-System Analysis: An Introduction. Durham: Duke University Press.

Wirth, Louis. 1938. "Urbanism as a Way of Life." American Journal of Sociology 44(1):1-24.

\section{ABSTRACTS}

The field of global urban studies has witnessed a "peripheral" turn since the 1990s, first led by the Los Angeles School of urban geographers, with a more diverse group of urban scholars who study the global South following. Challenging the city-centric view, as exemplified by the Chicago School's concentric model of urban growth, these scholars train their lens on urban peripheries, such as suburbs, small towns, and the sprawling hinterlands outside metropolitan regions. This essay discusses what can be gained from shifting the analytical lens from the city center to the periphery, and from Western cities to cities in the global South. Drawing upon the new scholarship on urban peripheries in India, it also identifies three major avenues for further investigation-the comparative method, center-periphery relations, and ways of life.

\section{AUTHOR}

\section{XUEFEI REN}

Associate Professor of Sociology and Global Urban Studies, Michigan State University 